\title{
Article
}

\section{The Experiences of Care Leavers (Post- care Adults) in Social Work Education}

Mayall, Helen, O'Neill, Teresa, Worsley, Aidan Richard clive, Devereux, Rose, Ward, Simon and Lynch, Darren

Available at http://clok.uclan.ac.uk/23251/

Mayall, Helen, O'Neill, Teresa, Worsley, Aidan Richard clive ORCID: 0000-00023925-3297, Devereux, Rose, Ward, Simon and Lynch, Darren (2014) The Experiences of Care Leavers (Post-care Adults) in Social Work Education. Social Work Education, 34 (2). pp. 151-164. ISSN 0261-5479

It is advisable to refer to the publisher's version if you intend to cite from the work. http://dx.doi.org/10.1080/02615479.2014.962019

For more information about UCLan's research in this area go to http://www.uclan.ac.uk/researchgroups/ and search for <name of research Group>.

For information about Research generally at UCLan please go to http://www.uclan.ac.uk/research/

All outputs in CLoK are protected by Intellectual Property Rights law, including Copyright law. Copyright, IPR and Moral Rights for the works on this site are retained by the individual authors and/or other copyright owners. Terms and conditions for use of this material are defined in the policies page.

\section{CLoK}

Central Lancashire online Knowledge www.clok.uclan.ac.uk

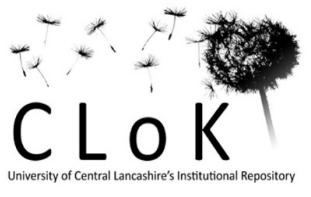


THE EXPERIENCES OF CARE LEAVERS (POST-CARE ADULTS) IN SOCIAL WORK EDUCATION

Helen Mayall ${ }^{\mathrm{a}}$, Teresa O’Neill ${ }^{\mathrm{b}}$, Aidan Worsley ${ }^{\mathrm{c}}$, Rose Devereux ${ }^{\mathrm{d}}$ and Simon Ward . $^{\mathrm{e}}$

${ }^{a}$ Manchester Metropolitan University

Department of Social Care and Social Work

799, Wilmslow Rd

Didsbury

Manchester

United Kingdom

M20 2RR

H.Mayall@mmu.ac.uk

01612472111

${ }^{\mathrm{b}}$ Manchester Metropolitan University

Department of Social Care and Social Work

Manchester

United Kingdom

M20 2RR

T.Oneill@mmu.ac.uk

01612474654

${ }^{\mathrm{c}}$ University of Central Lancashire

School of Social Work

Preston

United Kingdom

PR1 2HE

ARCWorsley@uclan.ac.uk

01772895466

d Person Shaped Support, in partnership with Liverpool Hope University

Liverpool

United Kingdom

L1 4BE

Rose.Devereux@pss.org.uk

01512913943

${ }^{\mathrm{e}}$ Liverpool John Moores University

School of Nursing and Allied Health

Liverpool

United Kingdom

L2 2ER

$\underline{\text { S.R.Ward@ljmu.ac.uk }}$ 
01512318108

With Darren Lynch.

Acknowledgements:

The authors acknowledge that this article could not have been produced without the contributions of:

Sara Simcock

Frances Young 


\section{THE EXPERIENCES OF CARE LEAVERS (POST-CARE ADULTS) IN SOCIAL WORK EDUCATION}

\section{Abstract:}

This paper explores the experiences of social work students on qualifying degree programmes in the UK who have previously been in care or 'looked after.' Using a sample drawn from three social work programmes in the North West of England, a semi-structured interview schedule was constructed, with the support of social workers who had been in the care systems, to examine the individual journeys of 11 students. This paper aims to explore, with this group of students, how their experiences relate to their decision to apply for a place on a social work course, their experience of admission and the duration of the programme. The paper is of particular relevance to social work educators and makes specific suggestions regarding how current practice in social work education might improve.

\section{Key words:}

Care leaver, looked after children, social work education, social work, curriculum development. 


\section{THE EXPERIENCES OF CARE LEAVERS (POST-CARE ADULTS) IN SOCIAL WORK EDUCATION}

\section{$\underline{\text { Introduction }}$}

This paper examines the experiences of social work students who were looked after children, or 'in care.' The research team comprised of five social work lecturers, from three 'post 92' universities in North West England and two recently qualified social workers, who had been

in care. The research study arose from our growing awareness that social work education and training raised particular issues for some of our students who had been in care. We were concerned that aspects of social work education, such as the content and process of the courses, might be disadvantaging this group of students. Through exploring the experiences of social work students who had been in care, we believe it might be possible to develop better pedagogical and institutional practices that build on their strengths and make the most of the experience that they bring to the social work profession.

\section{Literature and Review}

The notion that looked after children have, broadly speaking, negative educational outcomes is well established in the literature yet relatively little work has investigated the experience of care leavers in higher education (Who Cares Trust, 2012). For many leaving care, there is an expectation of 'instant adulthood,' skipping the transitional opportunity to explore, reflect and take risks, an opportunity which many young people access through higher education (Stein, 2006). Jackson and McParlin (2006) argue that social workers fail to give sufficient priority to educational attainment in their work with looked after children. They argue that this combines with low expectations of teachers and low educational attainment of many carers to produce poor outcomes. Sadly, the picture appears to remain the same across 
Europe. Jackson and Cameron (2011) looked at further education experiences of care leavers across five European countries and found little difference with regard to outcomes, barriers and, indeed, facilitators. They concluded that the educational opportunities of young people in and leaving care decrease progressively with age. Typical barriers included multiple placements and disrupted schooling, lack of encouragement and information. Interestingly, apart from the obverse of barriers, protective factors included educational priority from carers and the presence of someone who genuinely cared about their success, together with practical, financial and accommodation support. But, too often, the influences are negative:

...the evidence from our study suggest that the professionals and substitute carers with whom they come into contact are as likely to reinforce their class and genderbased assumptions about educational and career paths as to challenge them. (Jackson \& Cameron, 2011, p. 43)

However, in the literature, we see the importance of key figures in the development of life goals. Jackson and Cameron (2012) talk of clear evidence that well educated carers (whatever role they inhabit) make a 'substantial contribution' to progression. The Department for Children, Schools and Families (DCSF) similarly notes;

When care leavers looked back on what made the difference to sustaining their participation in college, it was having someone, whether it was a Personal Advisor, former foster carer or teacher, who kept in touch and asked how their day had been. (DCSF, 2009, p. 19) 
The literature also suggest that the key issue of support for care leavers is subject to a 'postcode lottery,' with Local Authorities varying widely in their implementation of the Children (Leaving Care) Act 2000. Jackson, Ajayi, and Quigley (2005) considered the largest single study of care leavers $(n=129)$ accessing further and higher education and noted the inconsistency amongst Local Authorities around personal advisors and insufficient financial support. Bilson, Price and Stanley (2011), The Who Cares Trust (2012) and DCSF (2009) similarly found evidence of variable performance in these areas. Clearly, the barriers faced by care leavers are not only high, but appear to be even tougher in some parts of the country. For Higher Education Institutions (HEIs) who are welcoming care leavers into degree programmes, this also suggests a likely wide variance in the support and readiness of those arriving, depending on the different geographical areas where they have been placed.

Interestingly, Jackson et al. (2005) noted the vital importance of open days in attracting and supporting care leavers' decisions to go to university, finding that many did not get enough information prior to starting and therefore missed potential grants. This accumulated to an average debt on graduation $22 \%$ higher than the national average. Key issues of finance and accommodation are clearly very important for care leavers, especially in the light of such mixed levels of support from Local Authorities. Martin and Jackson's (2002) study found that $75 \%$ of care leavers wanted more financial assistance and $45 \%$ experienced accommodation difficulties in higher education. Of course, putting these issues together we can conjecture that care leavers are therefore more likely to need to find employment during their degree and consequently have less time for study. Stress factors such as these clearly raise the risk of drop out (Jackson et al., 2005). It hardly needs to be added, but the introduction of new market fees for academic degrees up to a ceiling of $£ 9,000$ provides a substantial barrier in itself 
Having overcome such significant hurdles to access Higher Education, care leavers can then find themselves in extremely challenging situations. Sadly, evidence shows that accessing help from student support has proved difficult for care leavers. Tutorial support is clearly very limited and there appears to be an acute shortage of assistance for mental health difficulties:

Most of those who dropped out had endured severe physical, sexual or emotional abuse during childhood. Whilst these experiences tended to be relegated to the backs of their minds while they were in the relatively protected environment of school and foster home, once out on their own intrusive thoughts could resurface. (Jackson et al., 2005, p. 34)

Naturally, whilst managing issues in this territory, a care leaver at university might find difficulties in forming new relationships, feel isolated, struggle to ask for help and consequently find themselves unable to study. The challenge this raises, of course, is whether or not the care leaver should disclose their background. Understandably, some will choose to leave it all behind and others will be content to share. It is clearly vital that HEIs have well trained, sensitive staff in post who can work with post-care adults and afford them sufficient flexibility to meet their needs through the academic cycle (The Who Cares Trust, 2012). Of course, where accessing such support might involve an element of disclosure, this could be a barrier. Driscoll's (2013) research, notes that care leavers are 'notoriously hard to help, combining vulnerability and maturity with a sense of self-sufficiency and self-reliance' (p. 147), which may inhibit the development of supportive networks. When Cameron (2007) pursued these questions, she found that $58 \%$ of care leavers would 'feel OK' (p. 41) about 
asking for help, whilst 35\% said they 'preferred to sort out their own problems.' Underneath all this, of course, remain the stigmatisation experienced by those who have been looked after and a likely wish to disassociate themselves from negative stereotypes (Martin \& Jackson, 2002).

There is little evidence that universities are managing this problem in any concerted way. Jackson et al. (2005) found that (at the time of the study) only one HEI had a specific and comprehensive policy related to care leavers, whilst $95 \%$ of universities did not offer specific pastoral support to care leavers and a further $85 \%$ had no plans to provide additional study support. The Who Carers Trust (2012) identified how little the picture had changed. They found inconsistency in professional efforts to support any aspiration amongst care leavers and an absence of advice and support for care leavers in universities. Furthermore, when support is actually given, it tends to be poorly targeted and added to the care leaver's sense of stigmatisation. Significant shifts in policy (The Pupil Premium, 16-19 Bursary and raised tuition fees)...

...appear to have created a confusing picture on the ground and [this] is a direct result of a conscious localism agenda. The fragmentation this creates is harmful to lookedafter children and care leavers as it exacerbates the already existing postcode lottery (The Who Cares Trust, 2012, p. 4).

The current Coalition's 'Charter for Care Leavers' remains a voluntary code for local authorities to sign up to. The new Children and Families Act 2014 gives children in care the option of staying with their foster families until they are 21 , but otherwise fails to strengthen 
statutory obligations to care leavers, nor does it address the fragmentation and gaps in provision for them (National Care Advisory Service et al., 2013).

How the professionals within HEIs choose to engage with care leavers must be informed by the research evidence that exists, which we have tried to précis above. It is important to note that whilst we have considered this brief overview of the literature relating to care leavers in higher education, we have not discovered any material that relates specifically to care leavers who enter professional social work training in the UK. This is an interesting issue to consider as it may be, for example, that those who have been in care and thus 'exposed' to social workers, may find themselves attracted, or repelled, by the prospect of such a career.

\section{$\underline{\text { Methodology }}$}

This research project took the scenario of care leavers on qualifying social work courses in higher education as its starting point. Anecdotally, we were aware that there were often postcare adults within social work student cohorts and we began to reflect on how we might investigate this issue. Given our interest in understanding this subject matter from the perspective of those we were seeking to study, and their location in both academic and care environments, it felt important to explore notions of qualitative social research (Denzin, 1970). Whilst quantitative research may prioritise the collection of large scale objective 'facts', we felt, with Carey (2012) that we wished to 'privilege meaning and understanding' (p. 5) given the premise of the study. We were also aware that qualitative social research often gives voice to marginalised people (Ragin, 1994). Thus the project began from a social justice perspective, believing that social work research; 
... implies action, pursues social justice and collects systematic information in order to make a difference to people's lives. (Alston \& Bowles, 2013, p. 9)

Given the clear, unequivocal messages from research outlined above, we wished to consider two key questions: what experiences influenced the choice to train as a social worker (thinking particularly of the 'journey' to that decision) and how might social work programmes best respond to this group of students?

Mindful of a potentially small sample size, the universities of Central Lancashire, Liverpool John Moores and Manchester Metropolitan came together to explore the research topic, based largely on their shared experiences of the subject matter. The project was not funded by any third party, other than the time allowed for research by host institutions. The project's first decision was to recruit two qualified social workers who had personal, lived experience of the care sector. Project members based in academic settings were also qualified social workers. All took equal roles in the project construction, the group being conscious of evidence that academics can create barriers to involvement and undervalue the contribution of those with experience of receiving social work services (Branfield, Beresford \& Levin, 2007).

The primary research tool was an interview schedule, attuned to Robson's (1993) view that the research interview is, a 'kind of conversation; a conversation with a purpose' (p. 228). Whilst we were conscious of the issue this may create around the construction (as opposed to excavation) of knowledge, it felt important to avoid a heavily structured schedule which would be more likely to replicate hierarchal relationships (Mason, 2002; Silverman, 2006). The schedule was constructed within a focus group of social workers who had been in care, trialled with a volunteer and subsequently modified only slightly. To ensure independence, 
the interviewers only interviewed students from universities other than their own. Great attention was paid to a detailed participation information sheet, outlining the relevant detail on data collection, publication, anonymity and, of course, the right to withdraw at any time. Full ethical approval was received from each university.

Participants were recruited within each institution through an open call offering an initial discussion about the project. The criteria for inclusion were firstly, that the student was currently enrolled on a qualifying social work programme and, secondly, that they had spent some time living in the care system either in residential or foster care. Thirteen (13) students were recruited across a range of UG and PG programmes, but one student did not meet the criteria and one further student did not attend for interview. This led to a sample size of 11 , with the following composition (gender and ethnicity were self-identified):

Table 1 here. 
Although this is a small sample, it is interesting to highlight a few of its characteristics, perhaps most significantly, the average age of 34.36 (median 34), suggesting care leavers arrive at social work education some time distant from care. The study only managed to recruit one black participant, under representative of the typical social work programme's demographic, whilst the four male respondents were significantly over representative.

Interviews were all transcribed and formulated into both mundane and analytical files. Transcriptions were analysed on a thematic basis, both manually and by using NVivo software. Our thematic analysis model was drawn on a sequence of coding, theming and selecting, derived from Braun and Clarke (2006). As we look back on the data we gathered in this project we are conscious that we have engaged creatively with this process in a conscious, unavoidable attempt to reduce the reality of our participant's complex, fascinating, inspiring life journeys to a 'tell-able story'. We can also reflect that the more we look at things, the more complicated they become (Cronbach et al., 1980).

We present findings concerning participants' journey from leaving care to their decision to apply for a place on a social work course, followed by findings concerning their experiences on the course. Participants identify their motivation to embark on social work as their chosen career and how they overcame obstacles. They describe issues they encounter whilst being a social work student, issues that relate to their care experiences, both the beneficial insights that come from their particular experiences and the difficulties that they have faced. In terms of presentation, we have attempted to offer broadly representative quotes from the majority of respondents, or noted individual views as appropriate. We have numbered individual participants, to differentiate between their responses. 


\section{Journey from Leaving Care to Application to Social Work Course}

Ten of the participants were working in a key worker or support role, in social care, criminal justice or education, prior to applying for their course. Three themes became apparent in their reflections on this experience. Three participants identified key people at work who had strongly encouraged them to recognise their skills and potential to be a social worker, a further two participants spoke of continuing contact with foster carers who had similarly encouraged them. Secondly, this resonated with their own awareness of the limitations of their role and recognition that they needed a social work qualification in order to do more. Thirdly, whilst participants recognised that they could draw on their life experiences, both in care and subsequently, several also reflected that they had carefully considered their own readiness before applying.

\section{Encouragement and Experience}

Four participants had not acted on their thoughts about being a social worker until someone recognised their potential and this seemed to give them confidence to begin the application process:

My encouragement mainly in the past few years has come from my manager. She knew my background, she knew it very well. And she knew my aspirations in respect of wanting to go into this area. It was that encouragement from her that I think was the biggest thing, but also my mother as well. (Participant 7)

Some participants also used the support of colleagues to reflect on whether their care experiences might help them to make a successful application. 
...other people, other professionals, like some of the psychologists I worked with and some of the speech therapists, they were all saying to me, you know, why are you just working here, why when you can go and do more? (Participant 8)

Six participants described how they had taken time to gain the qualifications necessary to meet the entry requirements, but they also considered their readiness before applying for a social work course:

I did want to be a social worker, but I think when I had my own children I did change quite a lot and didn't feel ready to be a social worker because I still had a lot of... I think having children sort of brings up a lot of issues... and I thought I wasn't ready to do social work... (Participant 2)

In describing their experiences of working in the care sector, seven participants felt held back by the limitations of their role and were marginalised when decisions were being made:

...I thought you are always going on the extra distance, you are always fighting for people, you always want to do more, you're quite active, I'm in the wrong job - and I was...I felt that time, where I thought about it when I was younger, I'd kind of come to a point where I thought, 'I'm actually mature enough I think to be able to do that job... (Participant 11) 


\section{Care Experiences}

Whilst the frustration of working in unqualified roles was clearly an influence on their decision to become a social worker, the majority of participants were keen to emphasise that they were strongly motivated by their own care experience and for some it was clearly the primary motivator. A typical quote was:

I think if I wouldn't have been in care I wouldn't have wanted to do social work (Participant 9)

All participants gave examples of how they felt their care experiences would help them to be an empathetic and effective social worker:

...there was a girl that was in the same children's home I was in previously...I knew how she felt, and I could empathise with everything. I do not want to be one where somebody thinks, "You don't know what you are talking about; you have no idea what I am going through at all”, because I probably do...

...I want to be a social worker that really does care, not that just looks like they are caring, because I have had one of those before; it's not helpful. (Participant 1)

One participant reflected that a social worker who had recognised her unhappiness at a particularly difficult time had subsequently become an inspiration to her:

Yes and that one social worker, that's all it took, one person, and I could be that one person...And even if I work with a hundred children, if I mean what this social worker means to me... then it's worthwhile. So, it was like being on time and when 
I'm saying I'm going to be there, be there. It was taking me out, giving me a bit of a break from it because it's not easy being in care... (Participant 9)

\section{$\underline{\text { Being a Social Work Student }}$}

In describing their time as social work students, most participants were broadly positive about their experiences but identified key areas where social work educators could be more aware and sensitive in their teaching. The three most prominent themes in their accounts are presented below. These relate to issues surrounding disclosure curriculum and support during the course.

\section{Disclosure in the Application Process}

Anxiety about whether to disclose their care experiences begins with the application form and interview. Nine of the eleven participants thought it might go against them, even thinking that they could be excluded, due to having been in care. However, 8 did decide to mention it, at some point during, the application process.

It was a REALLY difficult decision because, again, it's that fear of being knocked back because of your circumstances; your previous circumstances. And, how much do you really want to disclose to somebody you don't know? At that point it's very sort of you don't know what they are doing with all these forms and you are not particularly comfortable. I was definitely not comfortable in disclosing too much information; I just briefly went over it. (Participant 1)

...even the young people in care, in the children's home that I work in, still have an expectation that social workers have been brought up with a silver spoon in their 
mouth, came out of University and straight into social work, you know. So even though I was applying for it, I thought, I wonder if it will go against me, the fact that I've actually been in care. I wasn't sure whether I would get through because of that. (Participant 6)

Despite initial uncertainty about how it would be received, 8 of the 11 participants did mention their care experiences, either on the application form, or during their interview. It is important to note that the recruitment method for the study would probably have skewed this as a proportion of the sample as it was likely to attract those more willing to disclose. But where respondents did so, some felt they were able to discuss their care experiences positively in the interview and that this worked to their advantage.

I did do it on the application and then in the interview, one of the things I did say, is when they were saying about your strengths, I was like, you know, I've got, I'm able to see it from the service users' point of view as well as the social worker. And I do think that had a great lot to do with me getting in to be honest with you. You see sometimes I still beat myself about that because then I think, oh great, I'm only getting in because I've been in care, but I suppose you can't win can you? (Participant 8)

Only one participant recalled being offered contact with support services as a result of identifying themselves as a care leaver on the UCAS application. 


\section{$\underline{\text { Disclosure when a Student }}$}

Once accepted on the course, understandably, most participants were selective in deciding who to trust with knowledge of their care experiences, recognising that the stigma persists even though they have moved on.

I don't want that stigma basically. I don't want people sort of, you know, thinking, oh goodness me, he was in care, sort of thing. Because I'm 44 years old now, it really doesn't make much of a difference.

I'm not the loudest person, I'm not the most sort of articulate person, but when I'm standing up there I'm comfortable about who I am, where I've come from, you know. The fact that people don't know that I've been in a children's home is neither here nor there, they will never ever know unless I tell them. All they'll see up there is someone who's pretty confident about themselves. (Participant 4)

Participants felt that they had knowledge that was valuable to other students but more than half the participants felt reluctant to share this in the large groups that formed much of their university experience.

You've potentially got over sixty students sat in a room being taught from the front, you know. Then in our breakout sessions, it's still, sixty-odd people sat in a room. Now, I think that's quite an intimidating environment in which you might want to, sort of, have an in-depth discussion. (Participant 3) 
This was compounded by having to manage other people's responses to disclosure. In the following extract, the student has been encouraged to contribute by the tutor:

Some of the tutors know some of my background, so they've asked me, 'and how did you feel about it?' So all the class know about it now. There was a few, I think, that said they felt sorry for me... I don't want anyone to feel sorry for me. I mean that's things that's happened in the past and I've overcome them, so I don't want anyone feeling sorry for me. I think because of what I've been through, and I've been through quite a lot actually with the domestic violence and growing up in care and running away and things like that and how bad I was, I think a few people find it hard to understand or believe that I'd been through so much. (Participant 6)

Whilst the above extract shows the potential problems with disclosure to the group, a common theme in the interviews was that students who have been in care feel they have valuable insights to contribute, particularly in challenging the negative perceptions of looked after children that can creep into the curriculum.

\section{Experience of the Curriculum}

Five participants highlight teaching about attachment theory as a point where they would like to question and explore issues in more detail. These participants, in different universities, heard messages in the teaching that troubled them. They wanted to probe further and some felt silenced and unable to pursue these issues within the session. 
I think it does bring up a lot of things... if you don't form an attachment at an early age then you're doomed, your life is doomed and I have been trying to find some research about people who have had... not really had a bad experience of being in care and, I am not saying that it was fantastic, but I don't think it was particularly a bad experience. (Participant 2)

...if you had not got positive attachments by six months old then you would be pretty much done for, kind of thing. I came away last year thinking "oh my word, I must be horrific, I have no attachments. I must be a terrible person”. This year we were told,.... "Well, actually you can reattach". So, it's not all what it was last year, so I felt so much better at that point. (Participant 1)

Social work programmes typically teach attachment theory early in the course and often within the wider context of human growth and development, where participants reported further frustrations.

We have had human growth and development lectures and I have not agreed with some of the lecturers. But I am not the sort of person that would want to say, "Well, actually..." to a lecturer, "I don't agree with that; I think what you have said is..." (Participant 1)

Again, this participant felt unable to speak about this in class but did sometimes share her thoughts with a trusted friend. '... I maybe would whisper to my friend next to me...(whispers).' The participant then reported similar frustrations in teaching about looked after children. 
It's quite negative. Yes it's quite negative about ex-looked after children. Yes, it's quite negative...I have come out of a couple of lectures and I have thought, you know, I am quite angry. Looked after children, they are likely to be abusers of alcohol, abusers of drugs, likely not to be educated and not likely to have jobs. And I am sat there thinking, I don't drink, I've never done drugs, I have had jobs and I am here. It's not always the case and it does make you feel a bit sort of second-class citizen almost. (Participant 1)

All participants wanted to contribute from their experience, but in different ways. Whilst some wanted to contribute to class discussion, others would prefer to contribute in ways that protected their confidentiality and anonymity.

I feel I can offer a different point of view actually, without having to go into any detail about my experience. But just saying, actually as somebody that's been through the experience, no my experience was different than that... (Participant 3)

I wouldn't mind like a few quotes being put into a research project that's anonymous. If the information can be used to understand, yes that's OK, but maybe not asking people to stand up and, does that make sense?.....

Yes, it's like a journal or something like that. Yes, like a kind of a bank of knowledge that students can draw on..... (Participant 5)

The interviews express the ways in which students in this study have received taught sessions that resonate with their care experiences. The lecturers who delivered these sessions might 
have been unaware that students in the group were responding to their teaching in this way. Participants made suggestions for improving practice.

If anything could come out of the research that could make it a sort of a better environment for people to talk openly....maybe if lecturers could say there is going to be people in the room who have been in care. I think you would probably feel more comfortable in speaking out in lectures when they talk about care-leavers...there is like a stereotype of people who have been in care and the statistics show there are not many people who come out of it very well..., in terms of education especially, and there is a higher level of offending of drug and alcohol misuse in people who have been in care, that Social Services have become involved with their children and they abuse their own children, and I know it's only me but I would like to say, actually that's not always the case.... (Participant 2)

Another participant pointed out that all their service user led sessions were with people who used adult services so the views of looked after children were not given first hand. She suggested that hearing from looked after children and care leavers during the course could make the achievements of looked after children more apparent. Social work courses have been required to involve service users and carers in their programmes a since 2002 (Department of Health, 2002). Currently the College of Social Work expects service users and carers to be involved in aspects of social work programmes as a condition of endorsement, for example in admissions and selection, design and delivery, assessment and evaluation (The College of Social Work, 2013). Although there is evidence of progress in including service users in social work teaching, it is less common to include young people and looked after children (Wallcraft, Fleishmann \& Schofield, 2012 ). 
First placement is an anxious but exciting time for many social work students. For participants in this study, there was a decision to be made, about whether to discuss their care experiences with anyone prior to placement, and anxiety about how their experiences of being in care would be viewed. Participants anticipated that placement could trigger memories and feelings from the past and, some questioned their readiness for the challenges of practice. Whereas many students might experience such self doubt at this stage in the course, for those who have been in care, discussing these thoughts involves a complex set of decisions about how much to disclose about their time in care. In the main, they coped alone with these feelings.

I don't know whether I would be very good, whether I wouldn't see things I was supposed to be seeing, or over vigilant I don't know, but there again, I thought maybe I would choose to do a placement with children and families next year because it's something I am a bit sort of afraid of so maybe if I do it I might really enjoy it.....I wouldn't be very comfortable about telling the tutor I didn't want to work with children in case they ask why, and I feel like I should be honest, but I don't know whether it would go against me, or it probably wouldn't, but you just don't know do you? (Participant 2)

Given that participants found stereotypes of care leavers persisted within the social work curriculum it is not surprising that they are unsure about what to say to tutors about their thoughts prior to placement. 


\section{Conclusions}

This article highlights the experiences of a number of social work students who have been in care. Although this group cannot represent the experiences of all such students, the eleven participants give insights that must prompt reflection on common practices in social work education. The findings suggest a number of potential areas for sensitive engagement with students who are post-care adults, and who might chose to share their experiences and insights both to enhance their own learning and for the benefit of social work education.

Participants' accounts indicate that they had been thinking about a career in social work for some time before making their application. Accounts of the application process then suggest that it would be helpful for care leavers to be reassured that equal opportunities and confidentiality practices apply to them too, so that they can make an informed decision whether to disclose this experience as part of their application. Such a statement helps address the inadequacies of the UCAS system and could be included in the general information about the course, alongside information about care leavers' bursaries.

Once accepted on the course, several participants' described a reluctance to seek support, especially from tutors, if it might lead to a disclosure of their care experiences. This is consistent with the self-reliance found in previous studies (Cameron, 2007; Driscoll, 2013; Martin \& Jackson, 2002) and reinforces the need for universities to offer specific support to care leavers and to publicise it. Participants raised similar issues about the curriculum, especially in relation to teaching about human development, attachment, and looked after children. In these sessions, when they had wanted to ask questions or contribute from their experience of being in care, they felt unable to do so. One barrier is clearly the persistence of stigma but participants found lectures in large lecture theatres were a particularly difficult 
environment in which to contribute. This highlights the importance of learning opportunities in small groups in enabling students to contribute from areas of personal experience, should they wish to. Whilst this paper focusses on the experiences of care leavers, we are aware that student groups include people with a wide range of life experiences who also might similarly benefit from small group teaching.

The potential consequences of disclosure can be seen in participants' accounts of having to 'manage' the responses of other students and, in some cases, further invitations from tutors to contribute. Despite awareness of these risks, most participants wanted to speak about their experiences, at some point during the course, to help others learn from their experiences, although not necessarily in front of other students. One participant suggested it would be helpful for social work lecturers to preface sessions about looked after children with a statement that they assume that care leavers are in the room. Another suggested inviting looked after children and care leavers' organisations to lead teaching sessions. There is the suggestion that such initiatives could counter the generalisations about care leavers as low achievers, and create a climate where students who have experiences to share feel more able to speak.

Word count $=5825$ 


\section{$\underline{\text { Reference List }}$}

Alston, M. \& Bowles, W. (2013). Research for Social Workers: An Introduction to Methods $3^{\text {rd }}$ edition. Abingdon: Routledge.

Berridge, D. (2007). Theory and explanation in child welfare: education and looked after children, Child and Family Social Work, 12(1), pp. 1-10. DOI: 10.1111/j.13652206.2006.00446.x.

Bilson, A., Price, J. \& Stanley, N. (2011). Developing Employment Opportunities for Care Leavers. Children and Society, 25(5), pp. 382-393. DOI: 10.1111/j.1099-0860.2009.00287.x.

Boffey, M. (2012). A foster carer's guide to inspiring and supporting care leavers to Higher Education. Retrieved from:

http://www.cardiff.ac.uk/advice/resources/Higher\%20Education\%20Toolkit.pdf, date accessed; $31^{\text {st }}$ July, 2013.

Branfield, F., Beresford, P. \& Levin, E. (2007). Common Aims: A Strategy to Support Service Users Involvement in Social Work Education. London: Social Care Institute for Excellence.

Braun, V. \& Clarke, V. (2006). Using thematic analysis in psychology. Qualitative Research in Psychology, 3(2), pp. 77-101. DOI: 10.1191/1478088706qp063oa.

Cameron, C. (2007). Education and self-reliance among care leavers. Adoption and Fostering, 31(1) pp. 39-49. DOI: 10.1177/030857590703100108.

Carey, M. (2012). Qualitative Research Skills for Social Work: Theory and Practice. Farnham: Ashgate. 
College of Social Work (2013). Endorsement of Qualifying Social Work Programmes: An Information and Guidance Booklet for HEI's. London: The College of Social Work.

Cronbach, L., Robinson, A.S., Dornbusch, S.M., Hess, R., Hornik, R., Phillips,

D.C.,...Weiner, S.S. (1980). Toward Reform of Programme Evaluation. San Francisco, CA: Jossey-Bass.

Denzin, N.K. (1970). The Research Act - A Theoretical Introduction to Sociological Methods. Chicago, IL: Aldine Publishing Company.

Department for Children, Schools and Families (DCSF) (2009). Realising young potential: supporting care leavers into education, employment and training. London: Cabinet Office.

Department of Health (DoH) (2002). Requirements for Social Work Training. London: Department of Health.

Driscoll, J. (2013). Supporting Care Leavers to Fulfil their Educational Aspirations: Resilience, Relationships and Resistance to Help. Children \& Society, 27(2), pp. 139-149. DOI: 10.1111/j.1099-0860.2011.00388.x.

East Midlands Care Leaver Activities \& Student Support (EMCLASS) (2012). Collation of Midlands University Provision for looked after / Care experienced young people. Retrieved July 31, 2013, from http://www.buttleuk.org/data/_resources/547/Midlands-Universitiesoffers-to-LAC-and-care-leavers-Feb2012.pdf.

Jackson, S. \& McParlin, P. (2006). The Education of Children in Care. The Psychologist, 19 (2), pp. 90-93. Retrieved from:

http://www.thepsychologist.org.uk/archive/archive_home.cfm?volumeID=19\&editionID=13 2\&ArticleID=986. 
Jackson, S. \& Ajayi, S. (2007). Foster care and higher education. Adoption and Fostering, 31(1), pp. 62-72. DOI: 10.1177/030857590703100110.

Jackson, S. \& Cameron, C. (2011). Final report of the YiPPEE project. Young people from a public care background: pathways to further and higher education in five European countries. Retrieved August 5, 2013, from

http://tcru.ioe.ac.uk/yippee/Portals/1/Final\%20Report\%20of\%20the\%20YiPPEE\%20Project \%20-\%20WP12\%20Mar11.pdf.

Jackson, S. \& Cameron, C. (2012). Leaving care: Looking ahead and aiming higher. Children and Youth Services Review, 34(6), pp. 1107-1114. Retrieved from:

http://www.journals.elsevier.com/children-and-youth-services-review/.

Jackson, S. \& Hojer, I. (2013). Prioritising education for children looked after away from home. European Journal of Social Work, 16(1), pp. 1-5. DOI:

10.1080/13691457.2012.763108.

Jackson, S. \& Martin, P. (1998). Surviving the care system: education and resilience. Journal of Adolescence, 21(5), pp. 569-583. DOI: 10.1006/jado.1998.0178.

Jackson, S., Ajayi, S., \& Quigley, M. (2005). Going to University from Care: report by the By Degrees Action Research Project, London: Institute of Education, London University.

Joint University Council Social Work Education Committee (JUCSWEC) (2008).

JUCSWEC: Code of Ethics for Social Work and Social Care Research. Retrieved February 2, 2014, from http://www.juc.ac.uk/swec-research-code.html. 
Martin, P.Y. \& Jackson, S. (2002). Educational success for children in public care: advice from a group of high achievers. Child and Family Social Work, 7(2), pp. 121-130. .DOI: 10.1046/j.1365-2206.2002.00240.x.

Mason, J. (2002). Qualitative Researching. London: Sage.

National Care Advisory Service, The Adolescent and Children's Trust The Care Leaver's Association, Voice, Barnardo’s, The Who Cares Trust The Fostering network (2013). Still Our Children: Case for reforming the leaving care system in England: Briefing for House of Commons Report Stage of the Children and Families Bill. London: Barnardos.

Northern England Care Leaver Activities and Student Support (NorthCLASS) (2012). Collation of University provision for looked after / care experienced young people. Retrieved July 31, 2014, http://documents.manchester.ac.uk/display.aspx?DocID=12241.

Ragin, C.C. (1994). Constructing Social Research. Thousand Oaks, CA: Pine Forge Press. Robson, C. (1993). Real World Research. Oxford: Wiley Blackwell.

Silverman, D. (2006) Interpreting Qualitative Data: Methods for Analysing Talk and Text ( $3^{\text {rd }}$ ed). London: Sage.

Stein, M. (2004). What works for young people leaving care? Barkingside: Barnardo's.

Stein, M. (2006). Research Review: Young people leaving care. Child and Family Social Work, 11(3), pp. 273-279. DOI: 10.1111/j.1365-2206.2006.00439.x.

Stein, M. \& Wade, J. (2000). Helping Care Leavers: Problems and Strategic Responses. Retrieved July 23, 2013, from http://www.york.ac.uk/inst/spru/pubs/pdf/helpingCL.pdf. 
The Who Cares Trust (2012). Open Doors, Open Minds: Is the care system helping lookedafter children progress into further and higher education? London: Who Cares Trust.

The Who Cares Trust (2013). The H.E. Handbook for Care Leavers. Retrieved July 32, 2013, from http://www.thewhocarestrust.org.uk/data/files/H.E._Handbook_England_Jan_2013.pdf.

Wallcraft, J., Fleischmann, J. \& Schofield, P. (2012 ). The involvement of users and carers in social work education: a practice benchmarking study. London: Social Care Institute for Excellence. 